\title{
Studies of FRAXA and FRAXE in women with premature ovarian failure
}

\author{
Anna Murray, James Webb, Sarah Grimley, Gerard Conway, Patricia Jacobs
}

\begin{abstract}
Recent reports suggest that women with FRAXA premutations have an increased likelihood of having premature ovarian failure (POF). We screened 147 women with idiopathic POF for the number of trinucleotide repeats at the FRAXA and FRAXE loci. We found six women with FRAXA premutations, including four familial and two sporadic cases, but no women with FRAXA full mutations. At the FRAXE locus there were no pre- or full mutations but there was an excess of small alleles with fewer than 11 repeats, including at least one small deletion at or near the triplet. The association of FRAXA premutations with POF confirms that premutation alleles can affect ovarian development or function or both. (F Med Genet 1998;35:637-640)
\end{abstract}

Keywords: premature ovarian failure; fragile X; premutation

The mean age of menopause is $51^{1}$ and premature ovarian failure (POF), defined as the cessation of menses for a period of more than six months before the age of 40 , affects approximately $1 \%$ of women. ${ }^{2}$ The causes of early menopause are largely unknown and include radiation and chemotherapy. Genetic causes of POF include galactosaemia, chromosomal anomalies, and mutation at individual genes. Primary amenorrhoea is at the most severe end of the POF spectrum and can be caused by various defects of the short arm of the $\mathrm{X}$ chromosome (Xp) that result in the clinical features of Turner syndrome. Abnormalities involving the long arm of the $\mathrm{X}$ chromosome (Xq), including deletions and $\mathrm{X}$; autosome translocations, can also cause ovarian failure, although amenorrhoea is usually secondary rather than primary. Xq abnormalities are not usually associated with the somatic features of Turner syndrome, which suggests that the phenotype is largely caused by loss of Xp genes. It is difficult to assess rigorously the effect of $\mathrm{Xq}$ deletions on ovarian function, as the presence of an $\mathrm{XO}$ cell line can rarely be excluded. There have been a few familial cases of $\mathrm{Xq}$ deletions with POF reported, and in conjunction with $\mathrm{X}$;autosome translocation data, two gene clusters or "super genes" on $\mathrm{Xq}$ have been proposed, POF1 in Xq26-q28 and POF2 in Xq13-q21. However, it is still unclear how disruption of these "super genes" can have the rather variable effect on phenotype that is evident from reported cases.
There are a number of individual genes, both autosomal and $\mathrm{X}$ linked, which have been proposed as POF genes: FSH receptor (2p16-21), ZFX (Xp21.3-Xp22.1), cyclin D2 (12p13), connexin 37 (1p35.1), FSH primary response gene (Xq22), SOX3 (Xq26-27), and FMR1 (Xq27). ${ }^{4-9}$ Despite extensive investigation of these genes and other known causes in affected women, approximately $60 \%$ of cases of POF have no obvious cause (G Conway, personal communication). This idiopathic group includes women who have an autoimmune disorder, as there is conflicting evidence for the link between autoimmunity and POF. Familial cases of POF have been reported, but in the clinic at the Middlesex Hospital they represent only about $4 \%$ of the total, including idiopathic and non-idiopathic cases. A family history of POF would suggest a genetic cause, but in most families no genetic abnormality has been found. ${ }^{10}$

The fragile $\mathrm{X}$ syndrome (FRAXA) is a relatively comon cause of mental handicap and is the result of expansion of a polymorphic CGG trinucleotide repeat in the $5^{\prime}$ untranslated region of the FMR1 gene. The normal number of repeats is five to 50. Premutations have 50 to 200 repeats which are associated with marked instability in repeat number during transmission but, because the CGG repeat within the FMR1 gene is not translated, the perceived wisdom is that the gene product, FMRP, is unaffected by the size of the CGG expansion in the premutation range. ${ }^{11}{ }^{12}$ Expansion above the repeat number of approximately 200 coincides with methylation of the repeat and the promoter, causing the gene to be silenced, and it is the absence of the FMRl protein that is associated with the clinical syndrome. Deletions and a point mutation in FMR1 have been described, which also prevent FMR1 protein production, and result in a clinical phenotype indistinguishable from that seen in the expansion mutation carriers. ${ }^{13}$ Approximately $50 \%$ of females with a full mutation are mentally handicapped, while $50 \%$ appear intellectually unimpaired.

The possibility that females carrying FMR1 expansion mutations may have an increased frequency of POF was first suggested by Cronister et al. ${ }^{14}$ Schwartz et al ${ }^{15}$ collected information on 240 women typed for the FRAXA CGG repeat, and found that $24 \%$ of women with premutations had POF compared to $14 \%$ of full mutation carriers and $8 \%$ of controls. In both studies the incidence of POF in full mutation carriers, although increased, was not significantly different from controls.

\author{
Received 1 September 1997 \\ Revised version accepted for \\ publication \\ 9 January 1998 \\ Correspondence to: \\ Wessex Regional \\ Salisbury District \\ A Murray \\ Human Genetics, \\ Hospital, \\ Southampton, Hants
SO16 5YA, UK \\ S Grimley \\ Middlesex Hospital, \\ Mortimer Street, \\ London, UK
}


Table 1 Frequency of FRAXA alleles on the $X$ chromosomes of 25 women with familial and 122 with sporadic $P O F$

\begin{tabular}{llccc}
\hline Allele & Repeats & Familial POF & Sporadic POF & Control \\
\hline Minimal & $0-10$ & 0 & 0 & 1 \\
Common & $11-40$ & 44 & 236 & 1237 \\
Intermediate & $41-60$ & 2 & 6 & 30 \\
Premutation & $61-200$ & 4 & 2 & 0 \\
Full mutation & $>200$ & 0 & 0 & 0 \\
Total & & 50 & 244 & 1268 \\
\hline
\end{tabular}

We reported the results of a preliminary study of 46 women with idiopathic POF. ${ }^{9}$ We found two women with fragile $\mathrm{X}$ premutations in this group both of whom had a family history of POF. In order to examine the relationship between Xq fragile sites and POF, we have compared the distribution of FRAXA expansion sizes in affected women and a control population. In addition, we examined triplet repeat number at the FRAXE locus, which lies approximately $600 \mathrm{~kb}$ distal to FRAXA. ${ }^{16}$ Large expansions at the FRAXE locus are associated with methylation of the FMR2 gene promoter, and males with the full mutation have mild mental retardation, while females appear unaffected. FRAXE was tested because of its close proximity to FRAXA, and also
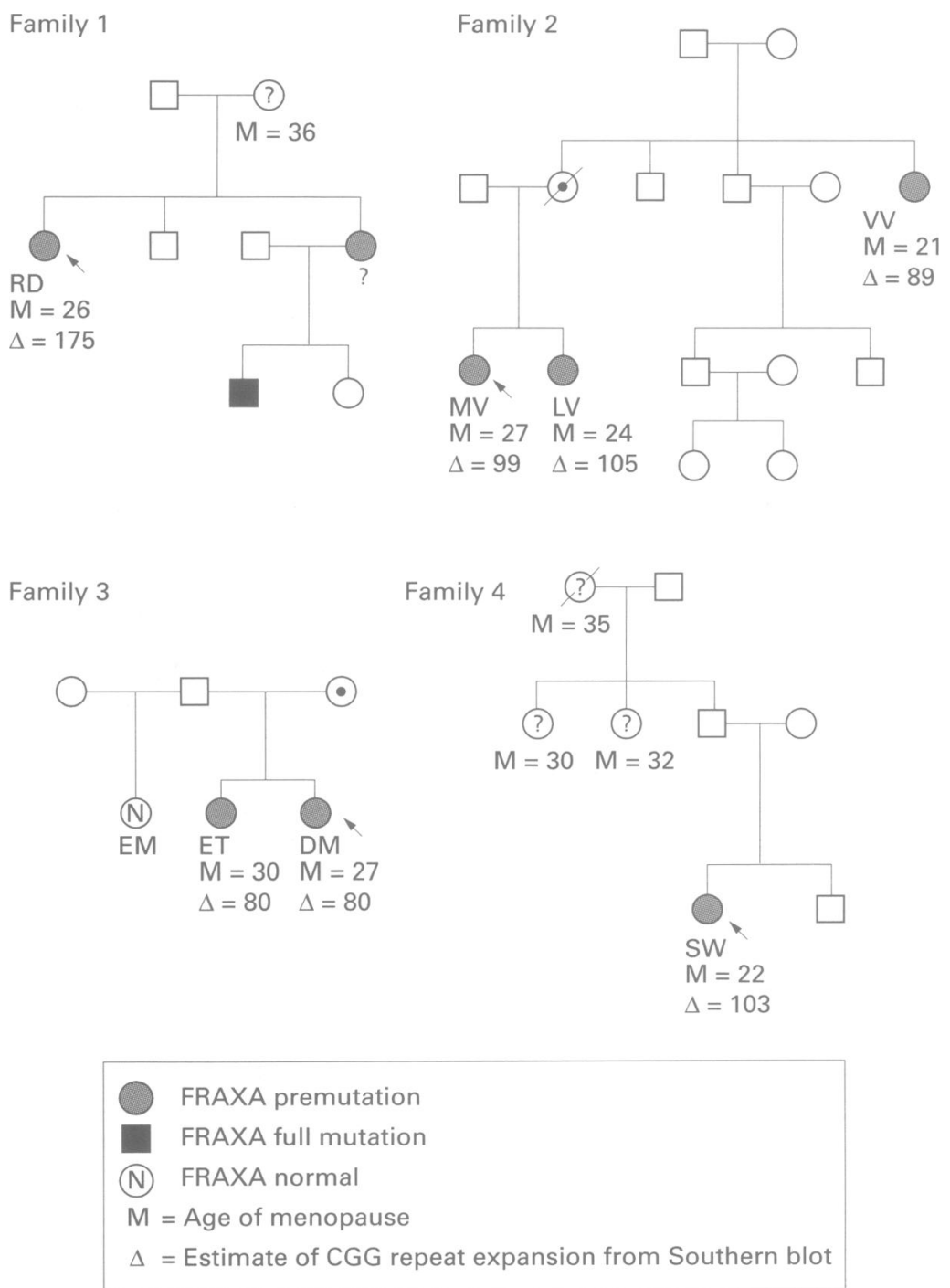

Figure 1 Pedigrees of four families with familial POF and concordant FRAXA premutations. ? indicates $P O F$ or fragile $X$ status unknown. In family 3, EM has no signs of POF at the age of 26. because earlier studies suggested that intermediate and premutation alleles of both FRAXA and FRAXE may have a phenotypic effect on learning. ${ }^{17}$

\section{Methods}

THE STUDY GROUP

A total of 129 women with idiopathic POF were included in the study following referral to the regional endocrinology clinic at the Middlesex Hospital, London. In addition, we screened 23 women diagnosed with idiopathic POF referred to the laboratory in Salisbury. Five POF cases among relatives of probands were not included in the sample. This gives 147 confirmed cases of idiopathic POF and therefore $294 \mathrm{X}$ chromosome haplotypes. Of these, 25 patients or 50 haplotypes were considered familial, as case notes or interviews indicated one or more female relatives with POF, while 122 patients or 244 haplotypes were considered sporadic. Seventeen percent of the study group were therefore familial, a considerably higher proportion than in the clinic as a whole. This is explained by the fact that very few of the non-idiopathic cases were familial, and we only tested women with idiopathic POF. There were, however, more familial cases than expected, and this probably reflects a bias of referral to the Middlesex Hospital, as it is a centre of expertise in ovarian failure. Detailed family histories were not taken for all patients and it is therefore conceivable that a proportion of the sporadic group may in fact have relatives with POF.

Control chromosomes were taken as the non-transmitted $\mathrm{X}$ chromosome from mothers of boys with learning difficulty. ${ }^{17}$ The first son to be tested was taken as the proband which gave 1268 women, each contributing one control haplotype.

\section{MOLECULAR SCREENING}

DNA was extracted from peripheral blood lymphocytes by the salt precipitation technique. ${ }^{18}$ The number of repeats at both FRAXA and FRAXE was determined by PCR amplification across the repeat region, using primers $c+f$, and 598+603, respectively. Primers $c$ and 598 were labelled with a fluorescent marker, and PCR products were separated on an ABI 377 Sequencer. ${ }^{17}$ In cases in which only a single allele for either FRAXA or FRAXE was detected by PCR, a Southern blot was carried out. To assess methylation status of the gene, we used a double enzyme digestion technique, $B S t \mathrm{ZI}+E c o$ RI for FRAXA and NotI+HindIII for FRAXE. BStZI and NotI recognise methylation sites within the FMR1 and FMR2 genes respectively. Southern blotting was by standard techniques, using probes StB12.3 for FRAXA $^{19}$ and OXE20 for FRAXE. ${ }^{16}$

\section{Results}

Our data on the FRAXA alleles are shown in table 1 , which is based on the number of $X$ chromosomes in each group. There was a significant excess of premutation alleles (classified as 60-200 repeats for the present study) in women with POF compared to controls (Fisher's exact 
Table 2 Frequency of FRAXE alleles in the $X$ chromosomes of 25 women with familial and 122 women with sporadic POF

\begin{tabular}{llrrr}
\hline Allele & Repeats & Familial POF & Sporadic POF & Control \\
\hline Minimal & $0-10$ & 1 & 5 & 9 \\
Common & $11-30$ & 49 & 237 & 1254 \\
Intermediate & $31-60$ & 0 & 2 & 5 \\
Premutation & $61-200$ & 0 & 0 & 0 \\
Full mutation & $>200$ & 0 & 0 & 0 \\
Total & & 50 & 244 & 1268 \\
\hline
\end{tabular}

test, $\left.\mathrm{p}=4.3 \times 10^{-5}\right)$. Two percent of chromosomes in the POF group carried premutation alleles, compared to none of the controls. The frequency of premutation alleles reached $8 \%$ in familial probands, and the difference from sporadic cases is significant (Fisher's exact test, $\mathrm{p}=0.0086$ ). These frequencies are greatly in excess of any population estimates for the frequency of FRAXA premutations. ${ }^{20}$

In familial cases in which a premutation segregated, all affected members tested carried the premutation allele (fig 1). In the two sporadic cases, family follow up provided only one additional family member for testing (fig 2), who was shown not to carry the premutation and is currently menstruating normally at 35 years old. In the second family with sporadic POF, both the mother and grandmother of the index case experienced an early menopause, at 42 and 41 years respectively, but they are not classified as POF. To date no members of this family, other than the proband, have been tested for FRAXA expansions. There were no full mutations or mosaics in either the POF population or the controls. Clinical details of the patients are reported elsewhere. ${ }^{21}$ The size of the premutations ranged from approximately 80 to 175 repeats while the age of menopause varied from 11 to 30 years. However, there was no obvious correlation between the age of menopause and premutation size. The distribution of FRAXA alleles among repeat sizes $0-60$ was not significantly different in the POF groups compared to controls $\left(\chi_{2}^{2}=0.39\right.$, $\mathrm{p}=0.824)$.

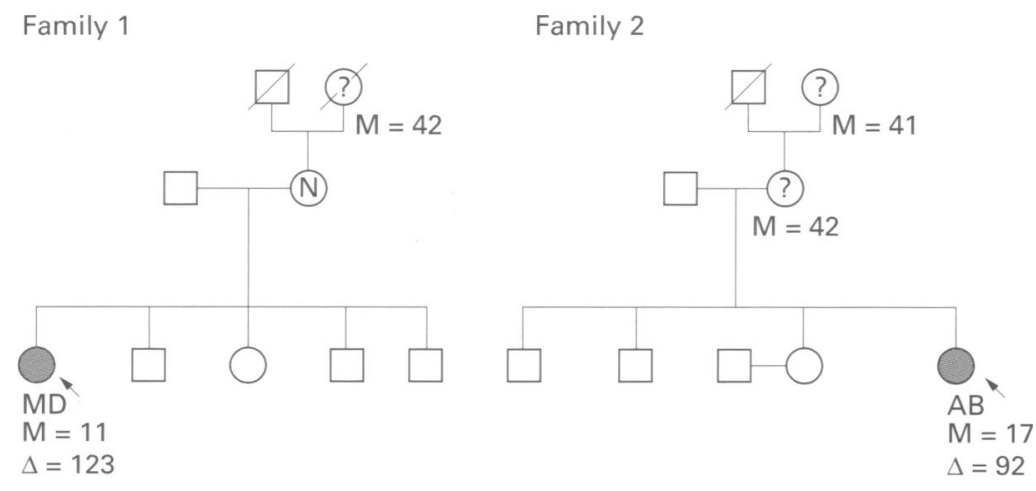

FRAXA premutation

FRAXA normal

$M=$ Age of menopause

$\Delta=$ Estimate of CGG repeat expansion from Southern blot

Figure 2 Pedigrees of two families in which POF is a sporadic condition.
Our data on FRAXE are presented in table 2. There were no premutations or full mutations in any woman, either in the POF group or the controls. There were no obvious differences in the distribution of FRAXE alleles between the two groups with the exception of small alleles with fewer than 11 repeats. There was a barely significant excess of small alleles in the $\mathrm{X}$ chromosomes from the women with POF $(2 \%)$ compared to controls $(0.7 \%)$ (Fisher's exact test, $\mathrm{p}=0.046$ ), but this was not expected and a conservative (Bonferroni) approach would double this probability. In the POF group, one of the chromosomes with a small allele must carry a deletion within the region flanked by the FRAXE primer set, because the PCR product in this person was $6 \mathrm{bp}$ smaller than would be expected from an allele with 0 GCC repeats. It is likely that the deletion lies within the DNA flanking the GCC repeat, but does not include the repeat itself. If this were so and the gene carried the modal number of repeats, 15 , the deletion would be $51 \mathrm{bp}$ in size. There were five other chromosomes in the POF group which carried FRAXE alleles with fewer than 11 repeats, a $6,8,9$, and two $10 \mathrm{~s}$. It is possible that some of these also represent cryptic deletions, and studies are under way to investigate this.

\section{Discussion}

We have tested a series of women with premature ovarian failure for the number of repeats at the fragile X loci, FRAXA and FRAXE. This follows the observation that women with FRAXA premutation alleles are at increased risk of early menopause. ${ }^{151622}$ A stimulus for the study was a woman who was being treated for premature menopause but subsequently discovered she was a fragile $\mathrm{X}$ carrier, following testing of her retarded nephew (fig 1 , family 1 ). A preliminary investigation of 46 women with POF detected a second patient with a FRAXA premutation in this group.' The study was therefore extended and we report results on 147 women with POF. Six carried FRAXA premutations, as did three of their similarly affected relatives, while none was detected in unaffected relatives or control chromosomes. Statistical analysis of these data indicate a significant association between FRAXA premutations and POF.

We found no cases of FRAXA full mutation in the women studied; however, this could be explained by ascertainment bias or small sample number. Previous studies of women in fragile $\mathrm{X}$ families found that POF was significantly more frequent in premutation carriers than in controls. ${ }^{14}{ }^{15}$ In the study by Schwartz et al, ${ }^{15}$ the incidence of POF in full mutation carriers was also greater than in controls, but did not reach statistical significance. However, recent reports from a world wide collaborative group on fragile $\mathrm{X}$ and $\mathrm{POF}$ provide overwhelming evidence that within fragile $\mathrm{X}$ families, $\mathrm{POF}$ is only associated with premutation carriers and not with full mutation or non-carrier relatives (manuscript in preparation).

It is usually assumed that the FMR1 gene has a detrimental effect only when inactivated, 
either by methylation, as in the full mutation, or by deletion or point mutation. ${ }^{13}$ However, the association between premutation and POF shows that this is not the case. Furthermore, there is preliminary evidence that intermediate and premutation alleles may have an adverse effect on intellectual function. ${ }^{17}$ In a survey of boys with learning difficulties, there was an excess of premutation and intermediate sized FRAXA and FRAXE alleles in the affected boys, suggesting that unmethylated fragile $\mathrm{X}$ alleles may have a phenotypic effect. The effect on intellectual performance differs from that on ovarian function, as the former includes intermediate alleles (40-60 repeats), while the latter appears to be restricted to premutations (60-200 repeats).

The apparent absence of an effect on ovarian function in full mutation carriers makes it difficult to conceive of a molecular mechanism which explains how FRAXA expansions cause POF. If FMR1 protein is absent from a cell, it may be that its function is provided by an alternative protein. However, if FMR1 is expressed, as in premutations, the alternative mechanism does not come into play and any adverse effect caused by the premutation is expressed. A recent paper ${ }^{23}$ reports that mutant transcripts for the myotonic dystrophy protein kinase gene are retained in the nucleus. Conceivably, premutation at the FRAXA locus affects the localisation or activity of FMR1 in a similar way, which is qualitatively different from non-expression in the full mutation.

The number of oocytes at birth determines the age of menopause; thus, the physiological age of an ovary is directly related to the number of oocytes it contains. It is possible that the FRAXA premutation reduces the number of oocytes at birth, either by increasing the rate of normal atresia or by reducing the number of oogonia. Murine studies have shown that FMR1 is particularly strongly expressed during the mitotic phase of oogenesis ${ }^{24}$ and so any subtle changes in expression at this time could dramatically reduce the number of oocytes, as the time of oogonial proliferation is restricted to a short period in mid gestation.

Unexpectedly, we also observed an excess of FRAXE alleles with fewer than 11 repeats in women with POF. This included one woman with a deletion of some of the sequence flanked by the primers used in the FRAXE PCR and raises the possibility that other small alleles may be cryptic deletions. Little is known about the function and expression of FMR2, but a deletion may disrupt the FMR2 gene directly or there may be a nearby gene, as yet unidentified, which is influenced by the deletion and is involved in ovarian function. Further studies should help to clarify this issue.

This study has confirmed an association between FRAXA premutations and POF, in women ascertained because of ovarian failure. We have shown that $1.6 \%$ of sporadic cases and $16 \%$ of kindreds with familial premature ovar- ian failure carry FRAXA premutations. Because of the obvious implications both to the patient and relatives, we suggest that patients with idiopathic POF be routinely screened for fragile X.

We would like to thank local clinicians for providing patients for inclusion into the study. We are extremely grateful to Sheila Youings for help with the data, and to Newton Morton for advice. We would also like to thank the Wellcome Trust for financial support.

1 McKinlay S, Jefferys $M$, Thompson B. An investigation of the age at menopause. $\mathcal{F}$ Biosoc Sci 1972;4:161-73.

2 Coulam CB, Adamson SC, Annegers JF. Incidence of premature ovarian failure. Obstet Gynecol 1986;67:604-6.

Powell CM, Taggart RT, Drumheller TC, et al. Molecular and cytogenetic studies of an $\mathrm{X}$;autosome translocation in a patient with premature ovarian failure and review of the literature. Am $\mathcal{F}$ Med Genet, 1994;52:19-26.

4 Aittomaki K, Lucena JLD, Pakarinen P, et al. Mutation in the follicle-stimulating hormone receptor gene causes hereditary hypergonadotropic ovarian failure. Cell 1995;82: 959-69.

5 Page DC, Disteche CM, Simpson EM, et al. Chromosomal localization of ZFX - a human gene that escapes X inactivation - and its murine homologs. Genomics 1990:7:37-46.

6 Inaba T, Matsushime H, Valentine M, Roussel MF, Sher CJ, Look AT. Genomic organization, chromosomal localization, and independent expression of human cyclin D genes. Genomics 1992;13:565-74

7 Simon AM, Goodenough DA, Li E, Paul DL. Female infertility in mice lacking connexin 37. Nature 1997;385:525-9.

8 Stevanovic M, Lovellbadge R, Collignon J, Goodfellow PN. SOX 3 is an X-linked gene related to SRY. Hum Mol Genet 1993;2:2013-18.

9 Conway GS, Hettiarachchi S, Murray A, Jacobs PA. Fragile $\mathrm{X}$ premutations in familial premature ovarian failure. Lancet 1995;346:309-10.

10 Mattison DR, Evans MI, Schwimmer WB, White BJ, Jensen $\mathrm{B}$, Schulman JD. Familial premature ovarian failure. $\mathrm{Am} \mathcal{F}$ Hum Genet 1984;36:1341-8.

11 Bell MV, Hirst MC, Nakahori Y, et al. Physical mapping across the fragile $\mathrm{X}$ : hypermethylation and clinical expresacross the fragile X: hypermethylation and clinical
sion of the fragile $X$ syndrome. Cell $1991 ; 64: 861-6$.

12 Oberle I, Rousseau F, Heitz D, et al. Instability of a 550-base pair DNA segment and abnormal methylation in fragile X syndrome. Science 1991;252:1097-102.

13 Meijer H, de Graaff E, Merckx DML, et al. A deletion of 1.6 $\mathrm{kb}$ proximal to the CGG repeat of the FMR1 gene causes the clinical phenotype of the fragile X syndrome. Hum Mol Genet 1994;3:615-20.

14 Cronister A, Schreiner R, Wittenberger M, Amiri K, Harris $\mathrm{K}$, Hagerman RJ. Heterozygous fragile $\mathrm{X}$ female: historical physical, cognitive, and cytogenetic features. $A m \mathcal{f} \mathrm{Med}$ Genet 1991;38:269-74.

15 Schwartz CE, Dean J, Howard-Peebles PN, et al. Obstetrical and gynecological complications in fragile X carriers: a
multicenter study. Am $\mathcal{F M e d ~ G e n e t ~ 1 9 9 4 ; 5 1 : 4 0 0 - 2 . ~}$

16 Knight SJ,, Voelckel MA, Hirst MC, Flannery AV, Moncla A, Davies KE. Triplet repeat expansion at the FRAXE A, Davies KE. Triplet repeat expansion at the FRAXE
locus and X-linked mild mental handicap. Am $\mathfrak{f}$ Hum Genet 1994;55:81-6.

17 Murray A, Youings S, Dennis N, et al. Population screening at the FRAXA and FRAXE loci: molecular analyses of boys with learning difficulties and their mothers. Hum Mol Genet 1996;5:727-35.

18 Miller SA, Dykes DD, Polesky HF. A simple salting out procedure for extracting DNA from human nucleated cells Nucleic Acids Res 1988;16:1215.

19 Roussaeu F, Heitz D, Biancalana V, et al. Direct diagnosis by DNA analysis of the fragile $\mathrm{X}$ syndrome of mental retardation. N Engl F Med 1991;325:1673-81.

20 Rousseau F, Rouillard P, Morel ML, Khandjian EW, Morgan K. Prevalence of carriers of premutation-size alleles of the FMR1 gene - and implications for the population genetics of the fragile X syndrome. Am f Hum Genet 1995; 57:1006-18.

21 Conway GS, Payne N, Webb J, Murray A, Jacobs PA. FRAXA premutations as a genetic marker for premature FRAXA premutations as a genetic mark
ovarian failure. Hum Reprod (in press)

22 Partington MW, Moore DY, Turner GM. Confirmation of early menopause in fragile X carriers. $\mathrm{Am} \mathcal{F}$ Med Genet 1996;64:370-3

23 Davis BM, McCurrach ME, Taneja K, Singer RH, Housman DE. Expansion of a CUG trinucleotide repeat in the 3' untranslated region of the myotonic dystrophy protein kinase transcripts results in nuclear retention of transcripts. Proc Natl Acad Sci USA 1997;94:7388-93.

24 Bachner D, Manca A, Steinbach P, et al. Enhanced expression of the murine FMR1 gene during germ cell proliferation suggests a special function in both the male and the female gonad. Hum Mol Genet 1993;2:2043-50. 